\title{
Contextualisation of the Current Knowledge and Technology Transfer-Related Literature: The Text Analysis
}

\author{
Vladimír BUREŠ* and Tereza OTČENÁŠKOVÁ \\ University of Hradec Kralove, Hradec Kralove, Czech Republic; vladimir.bures@uhk.cz; \\ tereza.otcenaskova@uhk.cz \\ * Corresponding author: vladimir.bures@uhk.cz
}

\begin{abstract}
The importance and relevancy of technology and knowledge transfer has been growing together with the interest and attractiveness for the organisations and institutions from both public and private sector. As a result, various literature focus on different aspects of this topic. Therefore, this paper focuses on the analysis of the current knowledge and technology transfer-related literature. It aims to identify the most mentioned keywords and topics to understand and contextualise the research field. The research methodology is based on the text analyses using the open access $\mathrm{KH}$ coder software. The correspondence analysis, co-occurrence network analysis, hierarchical cluster analysis and Self-Organising Map are used to reveal the results and the main topics of the discussed area. Crucial keywords strategy, policy and mission are identified. Furthermore, the technology and knowledge transfer are closely related to the learning and networking processes. The outputs also imply the three main word clusters including the academic environment, the organisational processes and projects supported by the software, and the information and knowledge management. Obviously, the discussed issues might provide the topical framework for reaching excellency as well as long-term competitive advantage.
\end{abstract}

Keywords: applied research; knowledge transfer; technology transfer; text analysis

JEL Classification: $\mathrm{I} 23 ; \mathrm{O} 31 ; \mathrm{O} 32$

\section{Introduction}

Science represents the activity with far-reaching implications for modern society. Researchers who appear as authors in a research article are a visible and easily quantifiable manifestation of an organisational scientific effort. The importance of knowledge and technology transfer is crucial for both the commercial and public areas (Marešová et al., 2020). Research institutions and universities are an important basis for unique intellectual property. These are dependent on the effective development of human resources and the management of related processes. In addition, the interaction with the commercial world has been becoming increasingly important as one of the tools for competitiveness increase. Apparently, there is a need to address the area at both levels, individual institutions and relevant social disciplines. Basic issues of support and management of related types of knowledge as a basis for subsequent possible improvement of efficiency need to be addressed as well. At the regional or national level, grants are offered to provide top researchers full 
service from practical matters such as accommodation, transport and food, to social ones such as the integration of other family members into society, children into schools, interest groups etc. It is not just the desire to work closely with colleagues that leads to the growth of extensive scientific collaboration and teams. Thanks to changes in the approach to scientific activity that attract the attention of scientists, the cooperation is essential. And that is not limited to the world of science. There are several examples of the huge impact that successful collaboration can have, such as the discovery of the causative agent of severe acute respiratory distress syndrome (Abraham, 2004). Research organisations are increasingly enthusiastic about the collaborative approaches and are encouraging their teachers and staff to work in a more integrative way, recognising that teams are likely to have a faster and fuller impact than individuals can achieve on their own. Institutions and financial agencies are setting up the infrastructure to encourage greater interaction, such as building large open laboratories where more researchers with the same interests can work in close proximity. Sharing ideas through the creation of interdisciplinary working groups and joint ownership of research projects is now also feasible thanks to the possibility to apply for the international grants. It is noteworthy that voluntary cooperation can be seen among institutions that would otherwise be considered competitive (Shrum et al., 2007). The aim of this paper is to analyse the main topics in the current research literature focused on knowledge and technology transfer. The article is structured as follows. After the introductory section, the methodology with a brief description of applied tools is introduced. Consequently, the results acquired from the analysis of available abstracts and keywords are presented. They are discussed in the next section with the emphasis put on the main topics and related perspectives. The final section concludes the paper.

\section{Methodology}

Analysis of research studies is based on the selection of appropriate, topical and highquality papers published and indexed in the Scopus database. The basic set of studies is selected by using Knowledge and Technology Transfer as the main search keyword. Moreover, eligibility criteria are established in order to include only relevant information resources. Their application reduces the number of analysable papers (see Table 1). The main eligibility criteria with their justification are:

- publication of the paper during the last ten years (the reason is to include only up-to-date and topical issues),

- records marked as articles or conference papers,

- authors' keywords contain "technology transfer" or "knowledge transfer" concepts (various papers are connected with the domain-specific topics such as analytical chemistry or pharmacology and technology and knowledge transfer is consider in a different way when compared to this study),

- the paper is written in English (the text-mining analysis and associated tools are prepared for English language only). 
Consequent analysis is executed in the KH Coder application, an open access text-mining and text-analysis software tool available at: https://khcoder.net/en/.

Table 1. Selection criteria

\begin{tabular}{|l|l|}
\hline Criterion & Number of research papers \\
\hline Topic: knowledge and technology transfer & 9,586 \\
\hline Time limitation: 2012-2021 & 5,346 \\
\hline Document type: article, conference paper & 4,354 \\
\hline Keywords: “technology transfer”, “knowledge transfer” & 1,127 \\
\hline Language: English & 1,091 \\
\hline
\end{tabular}

The following paragraphs briefly introduce methods used for the research papers analysis. The correspondence analysis is a multivariate statistical analysis applicable to the qualitative data. In this type of analysis, factor scores are reckoned from a frequency distribution to maximise their correlation (Petrovic et al., 2009). It is an effective technique which captures the correlations between features and classes and has been extensively used in different data mining tasks such as classification (Yang et al., 2017), feature selection (Zhu et al., 2010), and discretisation (Zhu et al., 2011).

The Co-occurrence network analysis helps to acquire a graphic visualisation of potential ties among concepts. The co-occurrence networks represent the collective interconnection of concepts grounded in their paired presence. Networks are generated by connecting pairs of concepts applying a set of criteria defining co-occurrence. For instance, concepts $\mathrm{X}$ and $\mathrm{Y}$ are considered to co-occur if they appear in a specific block of text. Another block of text may contain concepts $\mathrm{Y}$ and $\mathrm{Z}$. Linking $\mathrm{X}$ to $\mathrm{Y}$ and $\mathrm{Y}$ to $\mathrm{Z}$ develops a co-occurrence network of these three concepts. The co-occurrence patterns are significant for understanding structures, offering new insights into potential interaction networks, and revealing niche spaces shared by community members (Ma et al., 2016). For instance, in the case of co-word networks, Milojević et al. (2011) apply Jaccard coefficient to execute hierarchical clustering, for the same purpose, Yan et al. (2015) use Ward's methods. Delecroix and Epstein (2004) utilise an Ascendant Hierarchical Clustering algorithm based on the strength of association with cluster keywords; and Williams et al. (2016) define clusters with the Louvain community detection method. De la Hoz-Correa et al. (2018) use the community detection algorithm.

Generally, in the cluster analysis, it is not known which elements fit into which clusters. The data is reviewed to define the grouping or clusters (Zolfaghari et al., 2019). The cluster analysis is a technique for classifying a "body" of information into manageable, meaningful fragments. It represents a tool for data reduction which enables to develop subgroups which are manageable in more appropriate way. This technique examines the full complement of inter-relationship between variables. Derived from the general cluster analysis, the hierarchical cluster analysis is the major statistical method for finding homogeneous groups of cases based on the measured characteristics (Zhang et al., 2017). The clustering method uses the dissimilarities or distances between objects when forming the clusters.

Self-Organising Map (SOM) represents a dimensionality reduction algorithm generally used to represent a high-dimensional dataset as two-dimensional discretised pattern. 
Reduction in dimensionality is performed while retaining the topology of data present in the original feature space (Misra et al., 2020). It converts complex, non-linear statistical relationships among high-dimensional data into simple geometric relationships on a lowdimensional display (Leonard et al., 1999). Details related to the tool settings are presented in Table 2.

Table 2. Settings of the applied analytical tools

\begin{tabular}{|l|c|c|c|c|}
\hline Analytical Tool & $\begin{array}{l}\text { Correspondence } \\
\text { analysis }\end{array}$ & $\begin{array}{l}\text { Co-occurrence } \\
\text { network }\end{array}$ & $\begin{array}{l}\text { Hierarchical } \\
\text { cluster analysis }\end{array}$ & $\begin{array}{l}\text { Self-Organising } \\
\text { Map }\end{array}$ \\
\hline $\begin{array}{l}\text { Minimum Term } \\
\text { Frequency (TF) }\end{array}$ & 15,25 & 15,25 & 15,25 & 15,25 \\
\hline Distance & N/A & $\begin{array}{c}\text { Jaccard, Cosine, } \\
\text { Euclid }\end{array}$ & $\begin{array}{c}\text { Jaccard, Cosine, } \\
\text { Euclid }\end{array}$ & N/A \\
\hline Methods & N/A & N/A & $\begin{array}{c}\text { Ward, Average, } \\
\text { Complete }\end{array}$ & N/A \\
\hline $\begin{array}{l}\text { Type of edges } \\
\text { (words - words) }\end{array}$ & N/A & N/A & N/A \\
\hline
\end{tabular}

\section{Results}

Although analysis of available resources is performed on all combinations of available settings presented in Table 2, only selection of outcomes is presented in this section. The reason is that the application of different methods and various types of distance calculations provide similar results. The detailed analysis of these is not necessary for the purpose of this study.

Figure 1 presents the results of the correspondence analysis executed on the set of both, available abstracts and associated keywords. Provided graphs seem to be hard to read, however organisation of concepts is one of the interesting outcomes. One can also zoom in to find out the details. It is apparent that while increasing the term frequency reduces significantly the number of concepts included in abstracts, keywords still provide insight into the word correspondence. The reason is that while abstracts comprise a higher amount of words and thus potentially interesting word associations, word frequency lists, keywords in context, co-occurrences of concepts or terms, abstract-associated keywords are more precise on providing results in which general statements and empty phrases are not included. There are several clusters of concepts which can be identified. Abstracts contain words which are more or less associated with the same intensity. There are only a few exceptions. Three of them are connected with application domains, engineering, health and energy. Another three terms represent the managerial perspective which emphasises the necessity of long-term approach to knowledge and technology transfer, policy, strategy and mission. Moreover, keywords also stress the role of learning. There are also several clusters of topics identifiable. The first one is connected with the academic environment and universities, the second one focuses on managerial issues including support of related processes by software applications and the third one is associated with the information and knowledge management. 

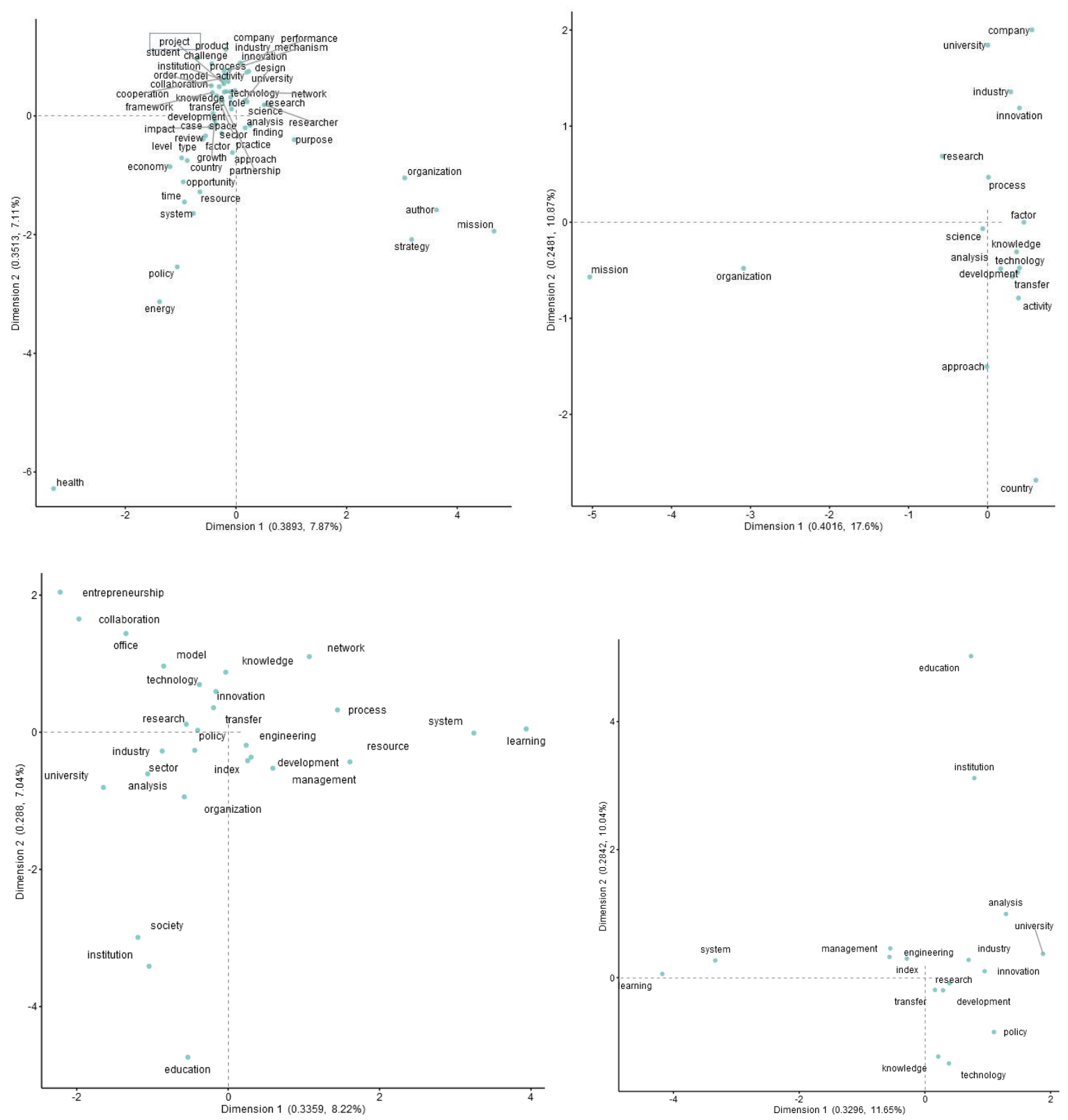

Figure 1. Correspondence analysis results: a) minimum TF 15, abstracts; b) minimum TF 25, abstracts; c) minimum TF 15, keywords; d) minimum TF 25, keywords. (Authors' research).

Results of the co-occurrence network analysis presented in Figure 2 partially support the outcome of the correspondence analysis. However, they bring quite less information as identified clusters are rather general than dealing with specific topics or issues. Especially when the term frequency is increased to 25 , the figures' content becomes too vague and associated with common terms from the knowledge and technology transfer domain. 

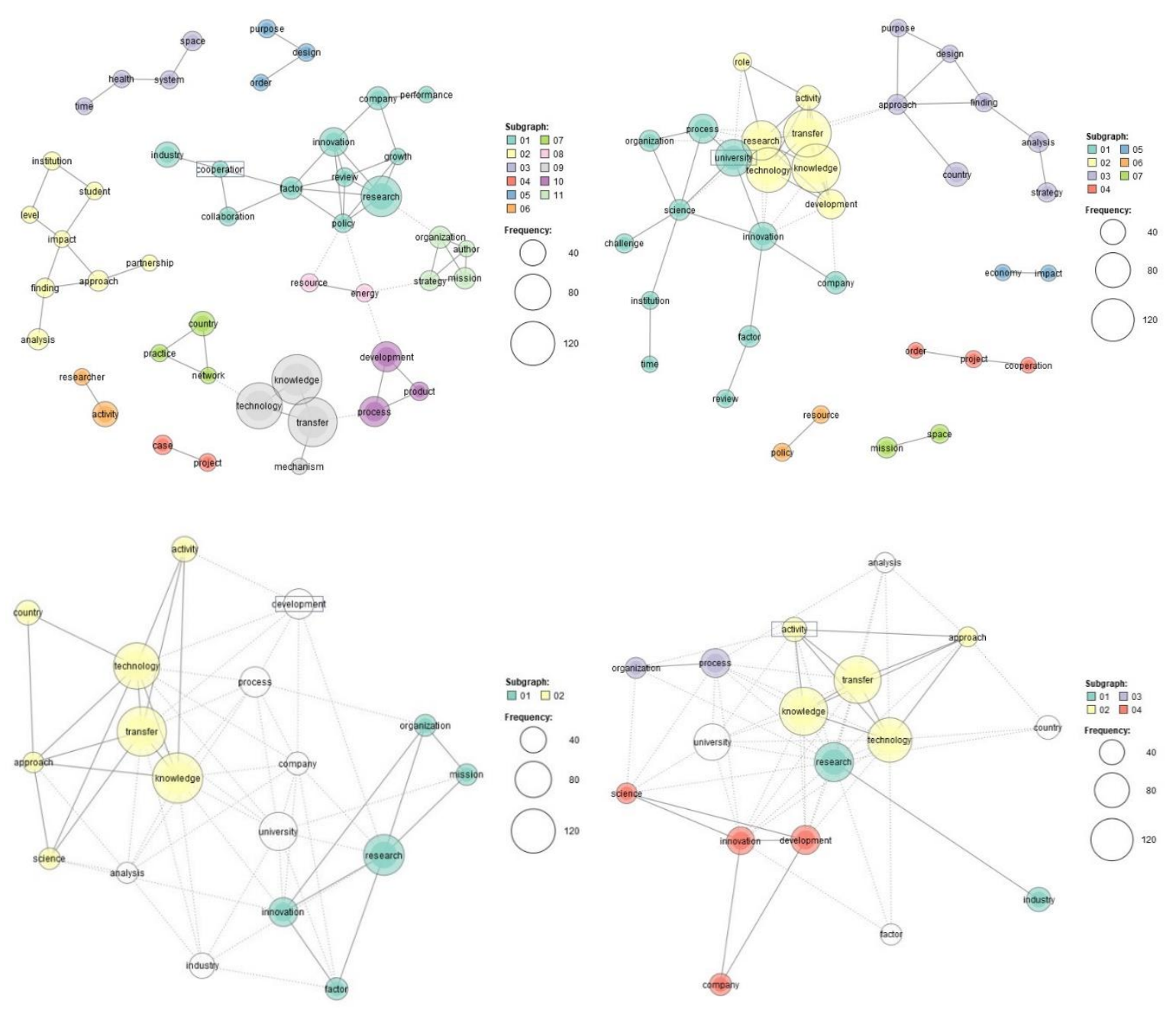

Figure 2. Co-occurrence network analysis of abstracts: a) TF15-Euclid; b) TF15-Jaccard; c) TF25-Euclid; d) TF25-Jaccard. (Authors' research).

Results of the co-occurrence network analysis presented in Figure 2 partially support the outcome of the correspondence analysis. However, they bring quite less information as identified clusters are rather general than dealing with specific topics or issues. Especially when the term frequency is increased to 25, the figures' content becomes too vague and associated with common terms from the knowledge and technology transfer domain.

Hierarchical cluster analysis in Figures 3 and 4 reveals that in case of abstract, there is one big cluster when a higher number of terms is analysed. However, the cluster consists of the organisational concepts related to both business, and academic environment. There are three dominant clusters if TF is increased. Moreover, there are five clusters when keywords are analysed. Always, the research role of universities is significant and the learning process is obviously relevant. All aforementioned outcomes are also supported by the SelfOrganising Map presented in Figure 5. 

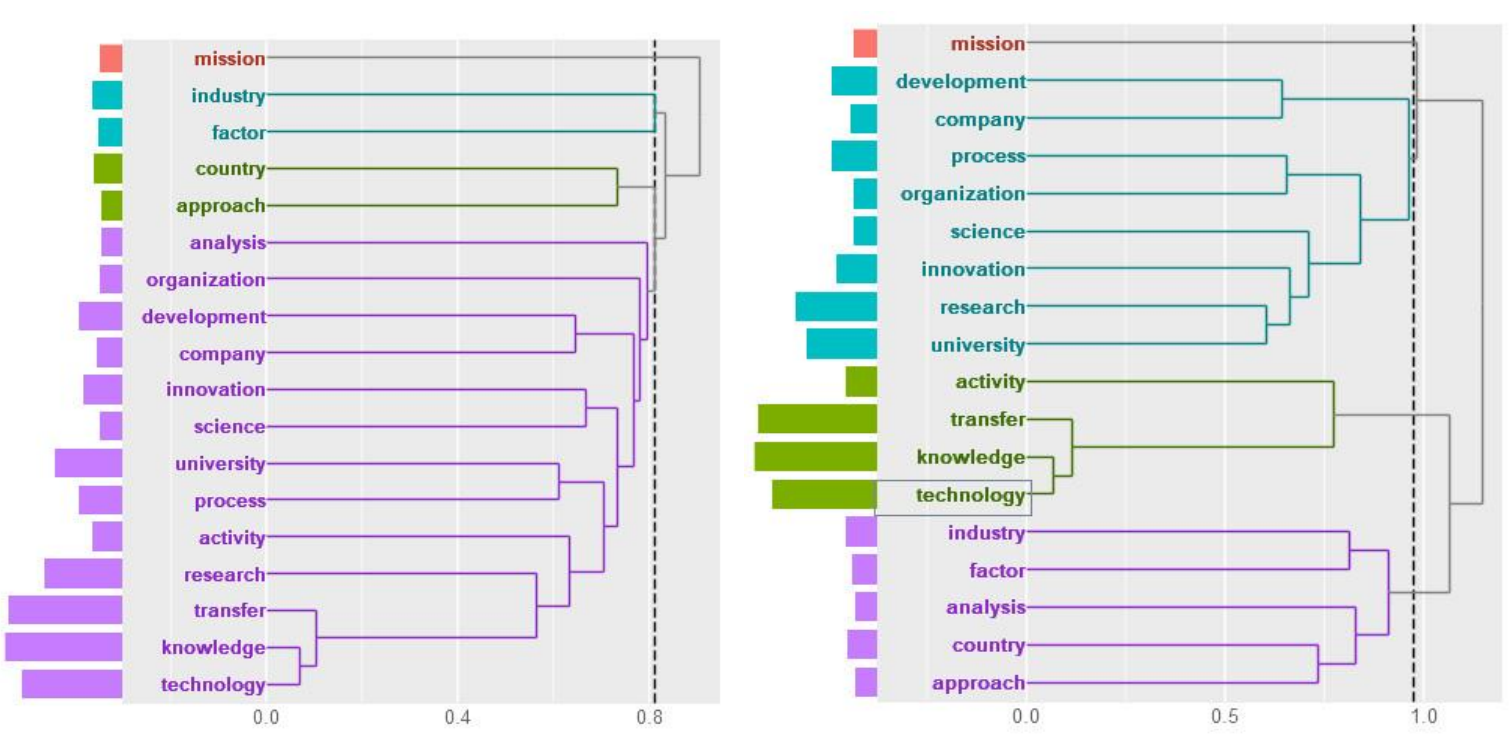

Figure 3. Hierarchical cluster analysis of abstracts: a) F25_average_Jaccard; b) F25_Ward_Jaccard. (Authors' research).

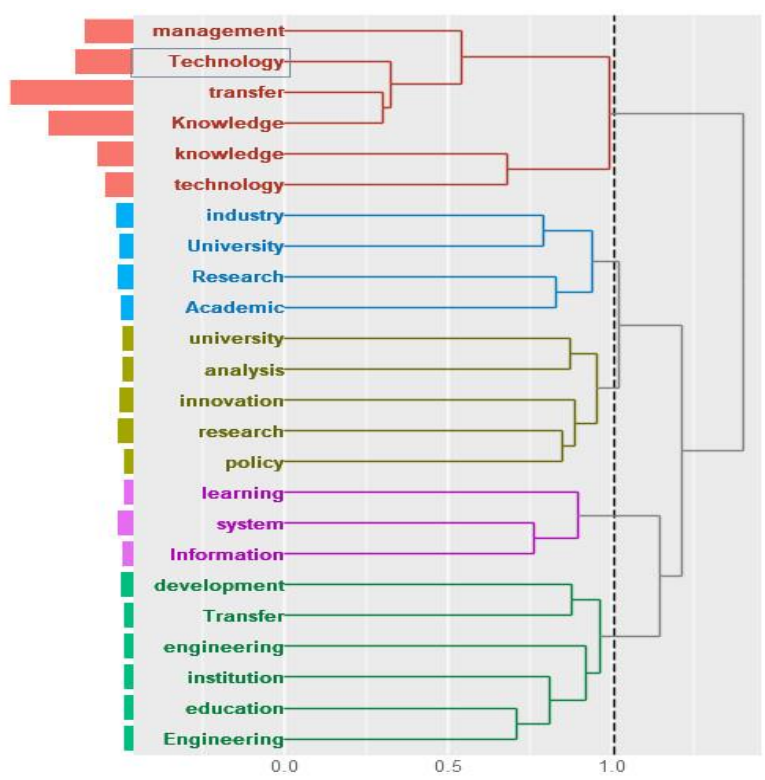

Figure 4. Hierarchical cluster analysis of keywords (F25_Ward_Jaccard). (Authors' research).

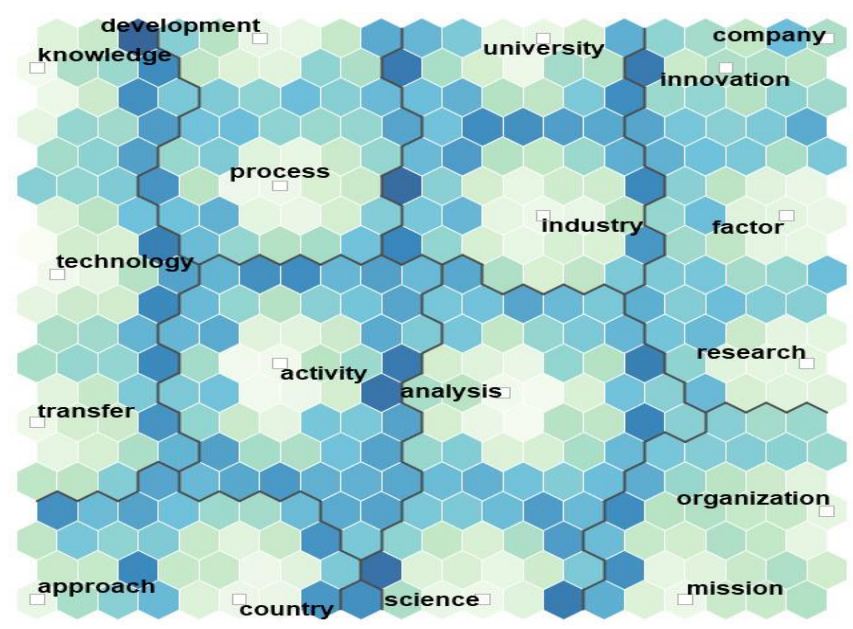

Figure 5. Self-Organising Map of abstracts. (Authors' research). 


\section{Discussion}

Currently, the organisations from both public and private sector care about their business potential and the possibilities how to commercialise their research, innovations, production outputs and other activities. The provided analysis proved that the topics related to necessity of conceptual, properly planned and long-termly focused approach are crucial. The policy, strategy and mission represent the important prerequisites in the successful implementation of the systematic approach to the continuously rising number of transferred technologies. Campbell et al. (2020) claims that the policy-makers represent one group of the important users of research outputs. This directly corresponds with the results. Moreover, the impact of knowledge transfer outputs is connected with the new policies and innovations. Except from these, the keywords society is mentioned proving that there is particular overlap to the societal aspects and scientific benefits which correspond to the benefits of technology and knowledge transfer in general.

Hand in hand, the abovementioned results reveal the importance of learning and education. These keywords indicate the significant impact of these. No matter whether at the academic level or at the business level, the learning should be ideally continuous and efficient in terms of the value added. The teaching, learning, training or sharing lead to awareness increase followed by better knowledge exchange in pursuit to support the transfer and innovation in particular.

Obviously, the networking plays an essential role (OECD, 2013). This is closely related to the fact that keywords like partnership, collaboration or cooperation occur frequently. Apparently, this implies the need to cooperate and coordinate the knowledge and technology transfer activities. The interconnections and relations might lead to synergies, higher participation of the stakeholders and their interaction. Therefore, the linkage between university and organisation, university and industry, organisation and industry or various other connections might be identified. The keyword entrepreneurship is frequent specifying the essential role of businesses. Furthermore, the keyword country occurs as well which implies the relevance of the implemented activities at the national level.

The results show that the important areas - within which the technology and knowledge transfer is discussed among the literature analysed - comprise for example health sector or the engineering. Healthcare is considered as one best captured area connected with the evidence-based case studies (Campbell et al., 2020). Within this field, various methods of knowledge transfer such as Knowledge Maps, Ontologies, Process Modelling, Lessons Learned, Best Practice Sharing, Story Telling, Job Rotation or Communities of Practice might be applied and implemented (Kruse et al., 2015). Engineering sciences are even called like "transfer sciences" (OECD, 2013) which prove their role in that field. Nevertheless, there are interdisciplinary differences in the transfer intensity as well as tools and channels used occur (OECD, 2013).

Among the word clusters, three main areas were identified. These keywords were repeating relatively often and therefore show the close relation to as well as importance of these for the technology and knowledge transfer. The first area is represented by the academic 
environment/universities. As mentioned above, the universities are an important part of the stakeholders as well as know-how holders. They provide particular knowledge, innovative ideas, theoretical support, technical background or resources needed. These might include the human, time, technological, space or another types. The value added for both parties is significant. For the company, the mentioned advantages might be attractive as they can reach relatively cheap workforce, interesting inputs and irreplaceable solutions thanks to the unbiased and 'fresh' academic perspective. For the academic institution, the possibility to solve 'real-world' problems and to be useful represent the crucial motivational aspects.

The second cluster of results prove that the process, project and software are present relatively frequently. These are relatively obvious as everything within organisations is related with particular processes. These can be just internal, external or both (see the networking discussion above). Currently, in a lot of organisations and institutions, the word project is used nearly for whatever. This fact explains its occurrence. Nevertheless, the technology and knowledge transfer itself usually represents a particular project involving various stakeholders, processes, tools and other components. The last element, software, is nearly ubiquitous for various purposes within a lot of daily activities and processes within the organisations.

The third cluster identifies the information and knowledge management. As these fields tackle with the information and knowledge which result in the technology and knowledge transfer, their presence is not surprising. No matter whether these are fully incorporated within the organisations or not, they represent importance supportive framework for smoother and more efficient technology and knowledge transfer. In case that the information and knowledge management is not managed well within the organisation, the problems might occur. This situation can be considered as a long-term issue in this domain (Bureš \& Brunet-Thornton, 2009). The latter might include the confusing roles of employees, their unclear responsibilities, the uncaptured or not well managed knowledge, the unused potential of intellectual capital of the organisation (Bureš, 2006).

Generally speaking, there are various tools for technology and knowledge transfer support. These comprise for example various R\&D and innovation grants, tax incentives, financial support to academic spin-offs, public-private partnerships or funding infrastructures (Campbell et al., 2020). Obviously, these tools for and channels of knowledge and technology transfer are not mentioned among the literature analysed. Also, the keywords identified miss doubtless the types of intellectual property or the aspects connected with the marketing of the technology and knowledge transfer. This was revealed even though the abovementioned issues represent important parts of the whole commercialisation process.

\section{Conclusions}

A lot of international, national and regional strategies, documents and reports emphasise the importance of research and the application of new knowledge in practice. The importance of innovation in promoting competitiveness and the further development of social, cultural and economic benefits followed by the overall progress is also highlighted (OECD, 2013). The responsible institutions and bodies focus on the appropriate supportive tools and 
improvement of the real results of publicly funded research and development and their implementation including the practical application more effectively.

Scientific and academic staff represent key stakeholders in the process of intellectual property protection at universities as they are originators of achieved results. However, the whole process will not be possible without professional support at the institutional level in a form of individuals helping with realisation of transfer in practice or specialised technology transfer office. Such experts should not only assess the current state of the art of the planned results from the available databases, but also assess the applicability of these results within the process of commercialisation. There is an important role of collaboration among the scientists, academicians and the supporting staff who guides others during all stages of the commercialisation process.

From the future development perspective, it is necessary to significantly and purposefully strengthen the motivation of employees in this area, optimise and continue to support their individual development and further education with regard to the constantly changing legislative and economic conditions. Furthermore, it is necessary to define the conditions and alternatives of commercialisation options, facilitate administration and show and bring examples of good practice of mutual coexistence of academic and business sector. Technology and knowledge transfer will then significantly contribute to intensive social interaction and communication between the two sectors, as well as to the effective sharing of information and knowledge between the academic environment and the commercial world. For these purposes, there should be ideally established and implemented the strategy at the national level. The availability of consultancy services and centres of the intellectual property protection and technology transfer is beneficial. These can also support the start-ups and spin-off companies as well as provide the targeted networking and consultancy services.

The aim of knowledge transfer is to identify the business potential of particular invention, exploit and commercialise it. This corresponds with the paper results including the significant connection of the knowledge transfer with the continuous, complex and systematic approach to the research and development activities. These might comprise the mission and policy statement, followed by the setting of the strategy and the fulfilment of the aforementioned. These are researched and discussed within both the knowledge and technology transfer-related literature, and all levels of the organisational and institutional framework of the technology and knowledge transfer in practice.

Acknowledgments: The research has been partially supported by the Faculty of Informatics and Management UHK specific research project n. 2107 “Integration of Departmental Research Activities and Students' Research Activities Support". Authors also thank Marek Zanker for his assistance.

\section{References}

Abraham T. (2004). Twenty-First Century Plague: The Story of SARS. Baltimore: The Johns Hopkins University Press. Bureš, V. (2006). Knowledge management and its implementation. In J. Cordeiro, V. Pedrosa, B. Encarnação, \& J. Filipe (Eds.), Proceedings of the 2nd International Conference on Web Information Systems and Technologies (WEBIST 2006) (pp. 115-118). Setubal, Portugal. 
Bureš, V., \& Brunet-Thornton, R. (2009). Knowledge Management: the Czech Situation, Possible Solutions and the Necessity for Further Research, In K. Dalkir (Ed.), Proceedings of the 6th International Conference on Intellectual Capital, Knowledge Management and Organisational Learning (pp. 95-102). Montreal, Canada.

Campbell, A., Cavalade, C., Haunold, C., Karanikic, P., \& Piccaluga, A. (2020). Knowledge Transfer Metrics. Towards a European-wide set of harmonised indicators. In M. Karlsonn Dinnetz (Ed.), EUR 30218 EN, Publications Office of the European Union. Luxembourg. https://doi.org/10.2760/907762

de la Hoz-Correa, A., Muñoz-Leiva, F., \& Bakucz, M. (2018). Past themes and future trends in medical tourism research: A co-word analysis. Tourism Management, 65, 200-211. https://doi.org/10.1016/j.tourman.2017.10.001

Delecroix, B., \& Epstein, R. (2004). Co-word analysis for the non-scientific information example of Reuters Business Briefings. Data Science Journal, 3(15), 80-87. https://doi.org/10.2481/dsj.3.80

Kruse, P., Kummer, C. \& Jannack, A. (2015). Empowering Knowledge Transfer in Healthcare: A Framework of Knowledge Transfer Methods. In Challenges and Opportunities in Health Care Management (pp. 319-328). https://doi.org/10.1007/978-3-319-12178-9_25.

Leonard, J. G., Pietrzyk, M., \& Cser, L. (1999). Mathematical and Physical Simulation of the Properties of Hot Rolled Products. Oxford, United Kingdom: Elsevier.

Ma, B., Wang, H., \& Dsouza, M. et al. (2016). Geographic patterns of co-occurrence network topological features for soil microbiota at continental scale in eastern China. ISME, 10, 1891-1901. https://doi.org/10.1038/ismej.2015.261

Marešová, P., Bureš, V., Štemberková, R., Matulová, P., Krejcar, O., Toman, J., \& Škodová Parmová, D. (2020). Od výzkumu po využivání v praxi: V̌̌e kolem transferu znalostí a technologií. Gaudeamus.

Milojević, S., Sugimoto, C. S., Yan, E., \& Ding, Y. (2011). The cognitive structure of library and information science: Analysis of article title words. Journal of the American Society for Information Science and Technology, 62(10), 1933-1953. https://doi.org/10.1002/asi.21602

OECD. (2013). Knowledge transfer channels and the commercialisation of public research. In Commercialising Public Research: New Trends and Strategies. OECD Publishing. https://doi.org/10.1787/9789264193321-5-en

Petrovic, S., Basic, B. D., Morin, A., Zupan, B., \& Chauchat, J. H. (2009). Textual Features for Corpus Visualization Using Correspondence Analysis. Intelligent Data Analysis, 13(5), 795-813. https://doi.org/10.3233/IDA-2009-0393

Shrum, W., \& Genuth, J. et al. (2007). Structures of Scientific Collaboration. Boston: The MIT Press.

Misra, S., Li, H., \& He, J. (2020). Machine Learning for Subsurface Characterization. Gulf Professional Publishing.

Williams, R., Runco, M. A., \& Berlow, E. (2016). Mapping the themes, impact, and cohesion of creativity research over the Last 25 years. Creativity Research Journal, 28(4), 385-394. https://doi.org/10.1080/10400419.2016.1230358

Yan, B. N., Lee, T. S., \& Lee, T. P. (2015). Mapping the intellectual structure of the Internet of Things (IoT) field (2000-2014): A co-word analysis. Scientometrics, 105(2), 1285-1300. https://doi.org/10.1007/s11192-015-1740-1

Yang, Y., Pouyanfar, S., Tian, H., Chen, M., Chen, S. C., \& Shyu, M. L. (2017). IF-MCA: Importance factor-based multiple correspondence analysis for multimedia data analytics. IEEE Transactions on Multimedia, 20(4), 1024-1032. https://doi.org/ 10.1109/TMM.2017.2760623

Zhang, Z., Murtagh, F., Van Poucke, S., Lin, S., \& Lan, P. (2017). Hierarchical cluster analysis in clinical research with heterogeneous study population: highlighting its visualization with R. Annals of Translational Medicine, 5(4), 75. https://doi.org/ 10.21037/atm.2017.02.05

Zhu, Q., Lin, L., Shyu, M. L., \& Chen, S. C. (2010). Feature selection using correlation and reliability-based scoring metric for video semantic detection. In J. E. Guerrero (Ed.), Proceedings of IEEE international conference on semantic computing (pp. 462-469). Palo Alto, CA, USA.

Zhu, Q., Lin, L., Shyu, M. L., \& Chen, S. C. (2011). Effective supervised discretization for classification based on correlation maximization. In R. Alhajj, J. Joshi, \& M. L. Shyu (Eds.), Proceedings of IEEE international conference on information reuse and integration (pp. 390-395). Las Vegas, NV, USA

Zolfaghari, F., Khosravi, H., Shahriyari, A., Jabbari, M., \& Abolhasani, A. (2019). Hierarchical cluster analysis to identify the homogeneous desertification management units. PLOS ONE, 14(12), e0226355.

https://doi.org/10.1371/journal.pone.0226355 